\title{
DOENÇA DA ARRANHADURA DO GATO: ZOONOSE SUBDIAGNOSTICADA
}

\author{
Eduarda Rodrigues Teixeira Cassianoㅜ; Joelma Moura Alvarez ${ }^{2}$ Selene Daniela Babboni² \\ ${ }^{1}$ Discente de Medicina Veterinária, Universidade Paulista (UNIP), São José dos Campos, SP. \\ ${ }^{2}$ Docente do curso de Medicina Veterinária, Universidade Paulista (UNIP), São José dos Campos, \\ SP.
}

DOI: $10.47094 /$ ICONRES.2021/27

\begin{abstract}
RESUMO
A doença da arranhadura do gato é uma zoonose, ocorre através da arranhadura, mordedura ou lambedura, de gatos infectados, em locais expostos como feridas ou mucosas no humano. Apresenta alto índice de infecção em gatos filhotes, apesar de assintomática na espécie; a doença é reconhecida pela sigla DAG, sendo caracterizada pela presença de bactérias do gênero Bartonella. O contagio entre felinos se dá através de pulgas da espécie Ctenocephalides felis, tornando-se os reservatórios da bactéria. Cães, ratazanas e morcegos, além de outros mamíferos, são reservatórios para o agente etiológico, porém sem grande relevância na transmissão do mesmo para o homem. Nos humanos a patologia apresenta sintomas como febre, lesões do tipo papulosas e linfadenopatia, atingindo principalmente crianças, idosos e pessoas com imunossupressão, ou enfermidade primária debilitante. Todavia o grande entrave desta zoonose é o subdiagnóstico na medicina humana, o que revela uma falta de multiprofissionais nos sistemas públicos e privados.
\end{abstract}

PALAVRAS-CHAVES: Bartonella; Zoonose; Felinos.

ÁREA TEMÁTICA: Medicina Veterinária

\section{INTRODUÇÃO}

A primeira descrição desta injúria, foi em 1950, pelo médico pediatra Robert Debré, sendo que outros estudos foram feitos, onde se descobriu que a espécie Bartonella henselae é a principal causadora da enfermidade (CHOMEL e KASTEN, 2010). Essa bactéria gram-negativa, em formato de bacilo, infecta os felinos domésticos através da pulga, vetor onde a espécie Ctenocephalides felis é a responsável por essa transmissão. Os gatos por sua vez, transmitem para os humanos através de lesões cutâneas ocasionadas por mordidas e arranhões, já os cães, apesar de possíveis portadores, raramente foram indicados como transmissores da doença após mordedura ou arranhão (BREITSCHWERDT e KORDICK, 2000; SOUZA et al., 2010).

Os gatos domésticos e errantes, devido ao seu estilo de vida e hábitos, além do crescimento 
exponencial no número desses animais, propiciam que o Felis silvestres catus, seja a principal espécie associada à doença da arranhadura do gato (LOPES et al., 2020). Após contato com arranhões ou mordidas do gato, o agente etiológico penetra no tecido lesionado, tendo capacidade de aderência em células endoteliais e eritrócitos, instalando-se em suas hemácias; sendo o sinal clínico mais comum no homem, a linfadenomegalia benigna (BREITSCHWERDT e KORDICK, 2000).

\section{METODOLOGIA}

A pesquisa foi realizada com fundamentação teórica em base de dados online, Scientific Eletronic Library Online (SciELO), Google acadêmico, PUBMED; contando com informações de livros e artigos científicos (língua portuguesa e inglesa) afim de descrever a doença e correlacionar com a espécie Felis catus, o gato doméstico, ressaltando sua importância como zoonose e apresentando medidas profiláticas que podem ser adotadas.

\section{FUNDAMENTAÇÃO TEÓRICA}

Tendo como sinônimo linforreticulose benigna, a denominada doença da arranhadura do gato (VELHO, 2001), é uma importante doença infecciosa de caráter zoonótico, intimamente ligada à espécie felina, pois esta atua como principal reservatório do microrganismo causador da doença. Além disso, a DAG é subdiagnosticada na espécie humana, pois geralmente não é indicada como uma possibilidade de diagnóstico diferencial em muitos casos de linfadenomegalia por exemplo (SOUZA, 2011).

A zoonose, retrata a pulga como vetor do agente etiológico; a bactéria do gênero Bartonella, essa conta com mais de 30 espécies, porém apenas 15 relacionadas a doenças que atingem humanos, sendo a $B$. henselae, a espécie comumente associada à DAG, tendo a capacidade de aderir e invadir os eritrócitos. A infecção caracteriza-se por duas fases, a primeira é fase a aguda, onde, a bactéria entra na corrente sanguínea e invade células endoteliais, e a segunda fase, a crônica, ocorre a multiplicação do patógeno e sua hospedagem no citoplasma das hemácias (LOPES et al., 2020).

Um estudo realizado com 200 felinos na cidade de São Paulo, avaliou a existência de anticorpos IgG anti- $B$. henselae, através de imunofluorescência indireta, obtendo como resultado $16 \%$ soropositivos, sendo a maior parte desses, filhotes entre 7 à 12 meses. Tais resultados podem ser explicados pelo desenvolvimento dos anticorpos humorais, que tem o seu declínio conforme o animal avança em idade (LOUREIRO e HAGIWARA, 2007).

A doença tem alta incidência, com 24 mil casos anuais nos Estados Unidos, e cerca de 2 mil na Holanda, com 400 mil gatos portadores nesse país, sendo usado como critério de diagnostico o contato prévio com o animal. Com ocorrência notória no outono e inverno, devido à alta frequência das fêmeas felinas iniciarem a gestação na primavera ou início de outono e assim no final do verão seus filhotes já estão propícios a transmissão. Aliado a isso, no mesmo período corresponde ao ápice 
da procriação das pulgas, porém, essa variação sazonal é observada apenas em países com clima temperado, a mesma não ocorre em locais de clima tropical (BOYLER e CHERRY, 1992; VELHO, 2001).

O vetor tem substancial envolvimento na doença, tendo em vista estudos realizados por Chomel e colaboradores (1996) onde gatos filhotes ao conviver com gatos bacterêmicos, porém desparasitados, não contraiam a bactéria, mas ao retirar pulgas de gatos bacterêmicos e ao colocá-las nos filhotes, esses por sua vez apesar de não desenvolverem sinais clínicos, se tornavam bacterêmicos. Concluindo assim que a transmissão entre gatos se dá através do vetor, que amplia o número de reservatórios felinos e atua indiretamente na doença humana.

A incubação da doença se dá em poucos dias à algumas semanas, o aparecimento da lesão primária ocorre de 3 à 5 dias após o contato e mordedura ou arranhadura do gato, surgindo no local do trauma, uma pápula eritematosa sem presença de prurido, após 2 ou 3 dias evolui para uma vesícula com crostas, posteriormente involui para uma mácula que pode permanecer até 3 meses. É mais comum a ocorrência de lesões nos membros superiores, podendo também ter apresentação de pústula ou nódulo, e progredir para uma ulceração, entretanto a forma mais marcante da doença é a linfonodomegalia, muitas vezes, sendo unilateral (CARITHERS, 1985, NOSAL, 1997).

A bacteremia é notória entre uma a duas semanas após o contágio, e prossegue de 10 a 24 meses dependendo do caso. Concomitantemente, nas primeiras duas semanas, ocorre o aumento do título de anticorpos IgG anti- $B$. hanselae, atingindo seu ápice na terceira semana, após esse período, ocorre uma queda que se mantem até a sexta semana. A bacteremia diminui e os anticorpos aumentam, pois esses controlam a multiplicação bacteriana. Devido a isso, a dosagem de níveis de IgG é realizada afim de indicar infecção por $B$. hanselae, passada ou recorrente, pois esses de mantem após longo período da infecção. Além disso, o histórico do paciente, avaliando histórico de contato com gatos, exclusão de outras causas de adenopatias, são cruciais para o diagnóstico (LOUREIRO e HAGIWARA, 2007).

A profilaxia é indispensável para evitar a incidência dessa enfermidade, como medida primária, sendo a pulga um vetor importante da doença, é crucial manter o animal desparasitado, evitando seu contágio. Por segurança, um manejo calmo com os animais, bem como contenção dos mesmos de forma segura, em especial dos felinos, pode evitar a arranhadura ou mordedura nos seres humanos, que culminaria com uma lesão cutânea no indivíduo. Sendo ainda relevante destacar a importância de evitar o contato com animais errantes, dos quais não se tem conhecimento do histórico clínico e ainda não conhecendo o perfil destes, poderia ocorrer um ataque ao indivíduo que tente contê-lo (BREITSCHWERDT e KORDICK, 2000; LOPES et al., 2020).

\section{CONSIDERAÇÕES FINAIS}

A doença da arranhadura do gato sendo uma zoonose de grande relevância, muitas vezes subdiagnosticada na medicina humana, e esquecida na medicina veterinária, uma vez que no ser humano não tem sintoma clínico patognomônico e no gato é assintomática, ressalta-se então a 
importância da profilaxia, consistindo em hábitos e cuidados necessários, como manter o animal livre de ectoparasitas e ter cautela com o manejo do mesmo, afim de evitar mordidas e arranhões, auxiliando no controle dessa enfermidade infecciosa e contribuindo para manutenção da saúde pública.

\section{PRINCIPAIS REFERÊNCIAS}

BOYLER, K.M.; CHERRY, J.D. - Cat scratch disease. In FEIGIN, R.D.; CHERRY, J.D. Textbook of pediatric infectious diseases. 3 ed. Philadelphia, W.B. Saunders, v.1, 1084-9, 1992.

BREITSCHWERDT, E. B.; KORDICK, D. L. 2000. Bartonella Infection in Animals: Carriership, Reservoir Potential, Pathogenicity, and Zoonotic Potential for Human Infection. Clinical Microbiology Reviews, 13(3), 428-438. doi:10.1128/CMR.13.3.428-438.2000

CARITHERS, H.A. Cat-scratch disease. An overview based on a study of 1200 patients. Am. J. Dis. Child., 139:1124-33, 1985.

CHOMEL, B.; KASTEN, R.W. (2010). Bartonellosis, an increasingly recognized zoonosis. Journal of applied microbiology. 109. 743-50. 10.1111/j.1365-2672.2010.04679.x.

CHOMEL, B.B. et al. Experimental transmition of Bartonella henselae by the cat flea. J. Clin. Microbiol., 34: 1952-6, 1996.

LOPES, G. A.; DA SILVA, L. G. P.; RISCH, A. L. C. Doença da arranhadura do gato: importância das medidas profiláticas. 2020: ANAIS CONGREGA - 16ª MOSTRA DE INICIAÇÃO CIENTIFICA v.16 - 2020, ISBN: 978-65-86471-05-2

LOUREIRO, V. S.; HAGIWARA, M. Levantamento de anticorpos anti-bartonella henselae em felinos domiciliados na cidade de São Paulo, estado de São Paulo e sua importância em saúde pública. Revista Brasileira de Ciência Veteterinária, 2007; 14 (1): 39-42

NOSAL, J.M. - Bacillary angiomatosis, cat-scratch disease, and bartonellosis: what's the connection? Int. J. Dermatol., 36:405-11, 1997.

SOUZA, A. M. de et al. Bartonelose: análise molecular e sorológica em gatos do Rio de Janeiro. Revista Brasileira de Ciência Veterinária, v. 17, n. 1, p. 7-11, jan/abr. 2010.

SOUZA, G. F. de Doença da arranhadura do gato: relato de caso. Ver Med Minas Gerais, 2011; 21(1): p.75-78

VELHO, P. E. F. Estudo das bartoneloses humanas e Bartonella henselae: infecção experimental, microbiologia, microscopia de luz e eletronica de transmissão. 2001. 233 p. Tese (doutorado) Universidade Estadual de Campinas, Faculdade de Ciencias Medicas, Campinas, SP. 